\title{
Traces of Early State formations in South East Georgia, Caucasus - response and impact on changes in the climate and environment
} Shiraqi Plane, South East Georgia, Caucasus

\author{
Konstantine (Kiazo) Pitskhelauri* Mikheil Elashvili** \\ * National Academy of Sciences of Georgia \\ * kote.pitskhelauri@tsu.ge \\ ** Ilia State University, School of Natural Sciences and Engineering \\ **mikheil_elashvili@iliauni.edu.ge \\ DOI: https://doi.org/10.52147/2667-9353/2021-1-60-68
}

Abstract. Study of past changes in environment and, its effect on human society delivers key information to reconstruct the hystorical past but also to project future changes and their effects. Study focus on South-East Georgia, Caucasus region, which represents natural polygon of long term changes in the environment.

Study area represents semi-arid Shiraqi plain in South-East Georgia (see the map below). It is characterized with annual precipitation $<600 \mathrm{~mm}$ and shows open dry steppic landscape today. However, recent data collected using remote sensing and archaeological studies, deliver evidences of early human inhabitation of this area, starting from the Paleolithic and forming a constant chain of active settlement through the time, until sudden abrupt at the end of the Bronze Age.

Geomorphologically Shiraqi plane represents $800 \mathrm{sqr} . \mathrm{km}$ of almost flat area with average height of $600 \mathrm{~m}$ above Sea level, surrounded by chains of mountains creating a natural walls surrounding the plane. There are almost no settlements in the area, devoid of water resources today. Archaeo-Botanic and soil studies assume that the region was covered by forests, Hydro modelling shows possibility of existence of well developed water network with a shallow lake in the center of plane. Remote sensing data and resent archaeological excavations at Didnauri site provides clear evidences of early state formation, with favorable paleo-environmental conditions.

The goal of current study is to shed light on historic changes in the environment of the region, its natural and anthropogenic factors and consequently response of human society on these changes.

Keywords: Cemetery, the gate, statehood

Study Approach. Since the first days of its existence, a human being is in the direct, active contact with the natural environment, trying to take advantage of it and at the same time depends on it. At present the human or anthropogenic impact on the environment represents a significant problem for humanity, which is reflected in the excessive use of natural resources and the concomitant changes in our living environment. However, the environmental change has its natural causes.

It is difficult to separate the rate of human impact on the environment and influence of the natural processes. Modern geoarcheology has gone beyond the boundaries of classical archeology, i.e. only human cultural heritage research; it includes anthropological, geomorphological and environmental researches to study people and its contemporary residential paleo-environment as a whole. The research of the past of the society of any region and era must start by the description of its contemporary palaeo-environment, because the entire system of the economic, social and political development of the society is built on these very variable and different in time basis. Here, still due to unidentified cataclysms, the entire eras with the different natural conditions are dramatically distinguished from each other, with its concomitant, substantial changes in public life. Iori Upland now largely lacks the 
vegetation; it is waterless and uninhabited. The present palaeo-geographical, palaeo-botanical and archeological data suggests that changes in forest, forest-steppe and steppe natural landscapes of Shiraqi plain - began in the Stone Age and lasted intensively dawn to end of Bronze Age. Most likely, in the semi-arid and critical climatic conditions unrecoverable changes in the natural landscapes of the region has begun due to influence of human's active economic activities.

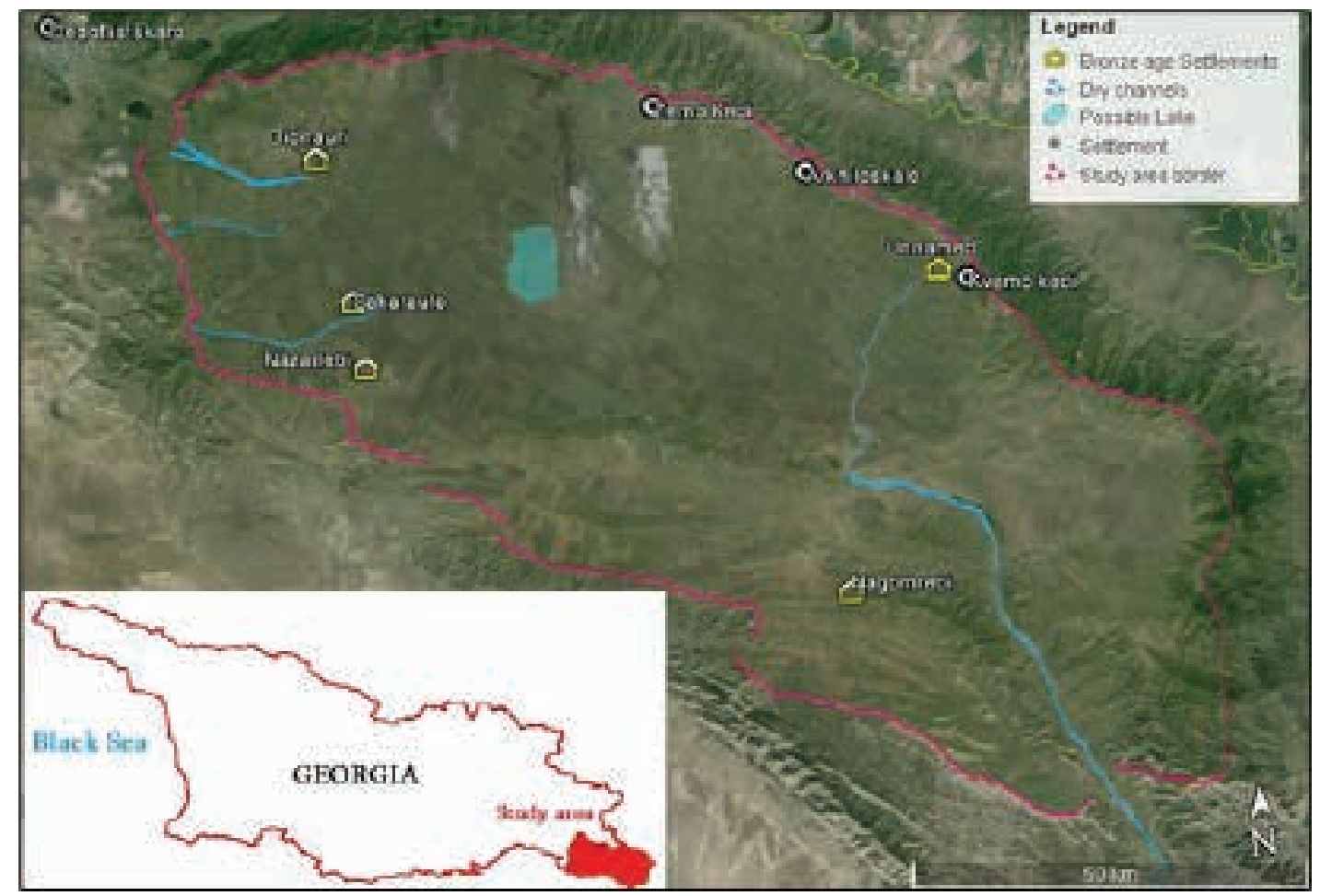

\section{Location of Study area of Shiraqi Plain}

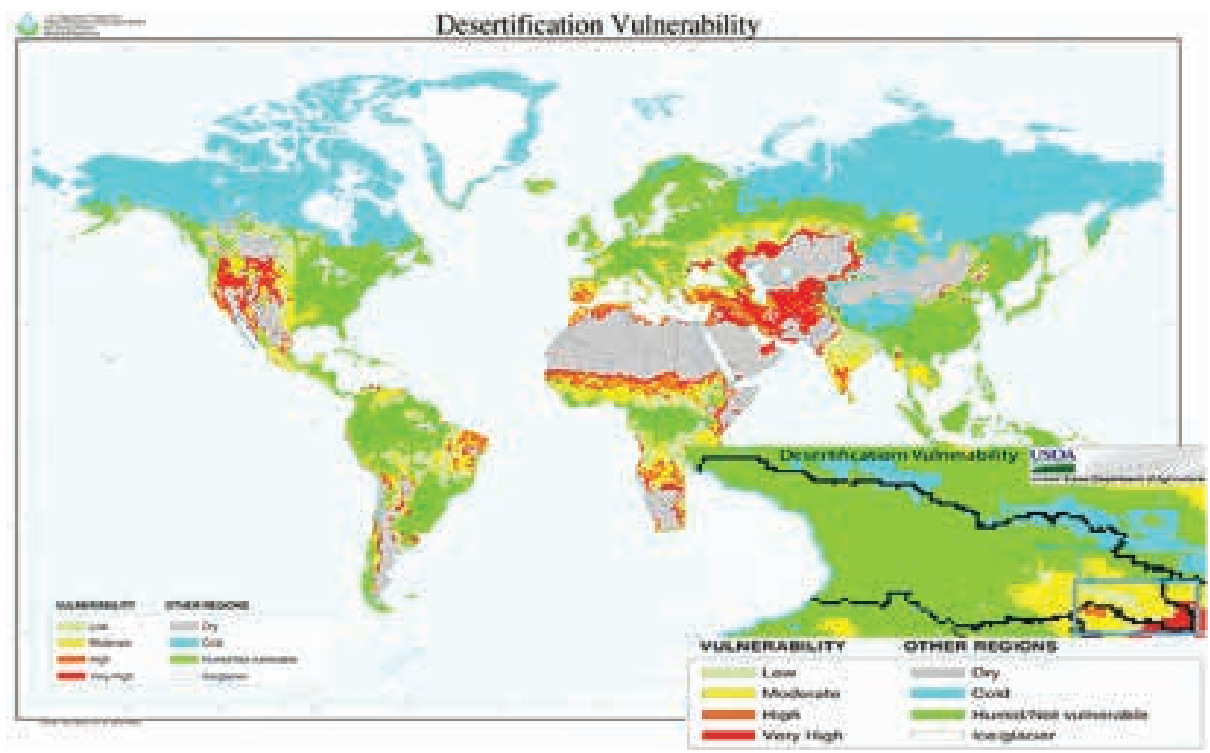

Desertification Vulnerability Map

Currently the region undergoes desertification process, in the convention of A/AC.241/27 adopted by UN Assembly in September 12 of 1994, among the regions, which are under the risk of desertifica- 
tion and draught, Trans Caucasus is also mentioned. And the south-easternmost part of Georgia gets into the moderate, high and very high risk zones in the world's Desertification Vulnerability map (1998) by The Natural Resources and Conservation Service (NRCS) of United States Department of Agriculture (USDA).

The research goal is: to shed light on historical changes in the environment of the region, its natural and anthropogenic factors and consequently, response of human society on these changes; to assess scale of ongoing changes in the environment, rate of desertification process during the past thousands of years and to evaluate evolution of local society and its reaction on these changes; to estimate available landscape and natural resources of past millennia and address the question of existence of early state formation in this region; and finally to project future possible changes in the environment of the region in wide and learn from the history lessons for future.

As mentioned above, Modern studies of the human past, today, actually represents a progressive geoarchaelogical direction, i.e, the multidisciplinary scientific researches, with the aim of the research of the consequent results of human evolution, human and environmental relations, human adaptation to the environment, development of natural resources, and socio-cultural aspects. As the allied field to the Earth's Quaternary geological era, it is aimed at the complex reconstruction of the ancient environment, communities and the environment, study of the human impact on the environment. At the same time, the maximum use of advanced digital technologies in the archeological researches is of great importance, which allows reaching new results through the data collection-fixation and analysis. The complex geoarchaelogical study of the Shiraqi valley is based on this approach and includes the following main aspects:

Complex archaeological Survey: processing and analysis of the results of available aerial and satellite imagery, topographic maps and field archaeological surveys in the GIS system. Close range aerial photogrammetric shooting of the specified sites using UAV; high-resolution orthophotos and digital terrain model will be derived as a result. Complex archaeological surveying results will allow making conclusions about the planning of entire cultural and historical area. The products derived by aerial photogrammetric shootings of the selected monuments will allow making the preliminary conclusions on planning and functional content of the monument, which makes the further archaeological excavations even more effective.

Archaeological Excavations at Didnauri site (possible ancient major city of late bronze age) have started in 2015 and continued extensively in 2016. At the present Burial mound next to city walls was excavated and studied, excavation of city walls and gates have been started this year. The total area of site is about 15 ha. General planning of city walls and main units were identified first at satellite images and later on studied in details from digital elevation model constructed based on Aerial photogrammetric survey.

Paleo hydrographic network modeling: on the basis of the Shiraki valley digital model the hydrographic network modeling will be carried out using the Arc Map software package, Hydro Toolbox model. The main streams and the corresponding water catchment basins will be modeled. The classification of streams to be carried out according to the received area. The modeled hydrographic network and the available ravines with temporary streams and the dry gorges in the Shiraki valley that are depicted in the satellite and aerial imagery will be compared to each other.

Palaeoclimate and vegetation reconstruction: palynological and paleobotanical analysis of the constructed stratigraphic profiles' selected samples will be carried out. Possible models of the palaeoclimate temporal change will be developed and the species of the common plants will be identified, 
which in turn will provide us with the information on the human possible economic activity in this region in the past millennia and on the human and environment interaction, as well as the anthropogenic component of the current desertification process.

Paleoenvironment reconstruction: continuous sediment cores will be taken for the creation of the stratigraphic profile in the selected sites of the study region, which represents the possible river and lake locations, archaeological monuments and has the traces of human economic activity in the past. Analyzing and dating of the samples will be carried out. The description-characterization of the relief, which has any meaning in the determination of its genesis, will be carried out through the implementation of morphographic and morphogeograpic researches. The role of the exodynamic processes in the formation of the relief will be studied. The studies will allow us to determine a connection between the physical-geographical conditions and the elements of the relief. Morphometric-morphographic indicator of the change in relief in the second half of the Holocene will be identified on the basis of the analyzing the stratigraphic results and studying the contemporary morphodynamic processes in the study region. Based on the results obtained in this way will make it possible to predict the geomorphological and landscape processes.

\section{Archaeological Excavations on Didnauri Bronze Age Settlement - Brief Update Sep 2016}

Active phases of excavation in Didnauri archaeological site began in 2016. The only work implemented before was the excavation of trial trenches in 2015. Excavations are taking place on to sites: on a sizeable burial to the north from the Didnauri Ciry and directly inside the City, namely on the citadel situated in the north-western corner of its outline.

\section{The Burial}

The Didnauri Burial mound consists of fifteen hillocks spread of ten hectares. Placed in a form of a circle around a ritual stage the hillocks presumably represent ancestral burials. Each hillock is composed by burials of small ground embankments and holes strictly enclosed by masonry walls to a single ancestral place.

Excavation of the central part of one of the hillocks showed five layers of burials stacked atop each other. All the layers age back to approximately X-XIII century B.C. only two cases exit the abovementioned timeframe where the two burials of the lowest layer are dated as of the later XIV B.C. thus allegedly belonging to the so called South Caucasian culture. One of the burials (N35) holds in a bronze sword belonging to a high ranking military person who was assassinated using an Anatolian bladed arrow.

\section{The City (Citadel)}

The City of Didnauri is spread of 15 hectares, with city wall being of seven meters width. Its construction material consists of some timber logs, flood plain boulders and clay. Apparently the same material was used to build the fence of a 12 meter wide citadel in the north-western corner of the city. The eastern part of the city's central area presumably held a water reservoir. The reservoir inside the city could be fed by the channel system (with small reservoirs) coming in from a creek "Didnauri" with headwaters in the mountain to the west from the city.

The city is surrounded by a 12 meter wide and 3,5 meter deep defense trench also presumably filled with water at the time.

This year's excavations of two trenches (100 meter long, 10 meter wide) made on the citadel (as it 
can be seen from aerial imagery), on the depth of 70 centimeters showed a 12 meter wide city wall. Inside the fence there is a small square and a street paved with smaller-grained rubble. The street used to lead into a 14 meter long columned hall.

In the inner perimeter of the citadel some massive rock constructions have been found. These constructions have the same age the abovementioned paved square. A Fasteners was found lying on the paving of the square in front of hall building. Preliminary findings suggest the age of the Fasteners to be XIII century B.C.

\section{Annex Illustrations:}

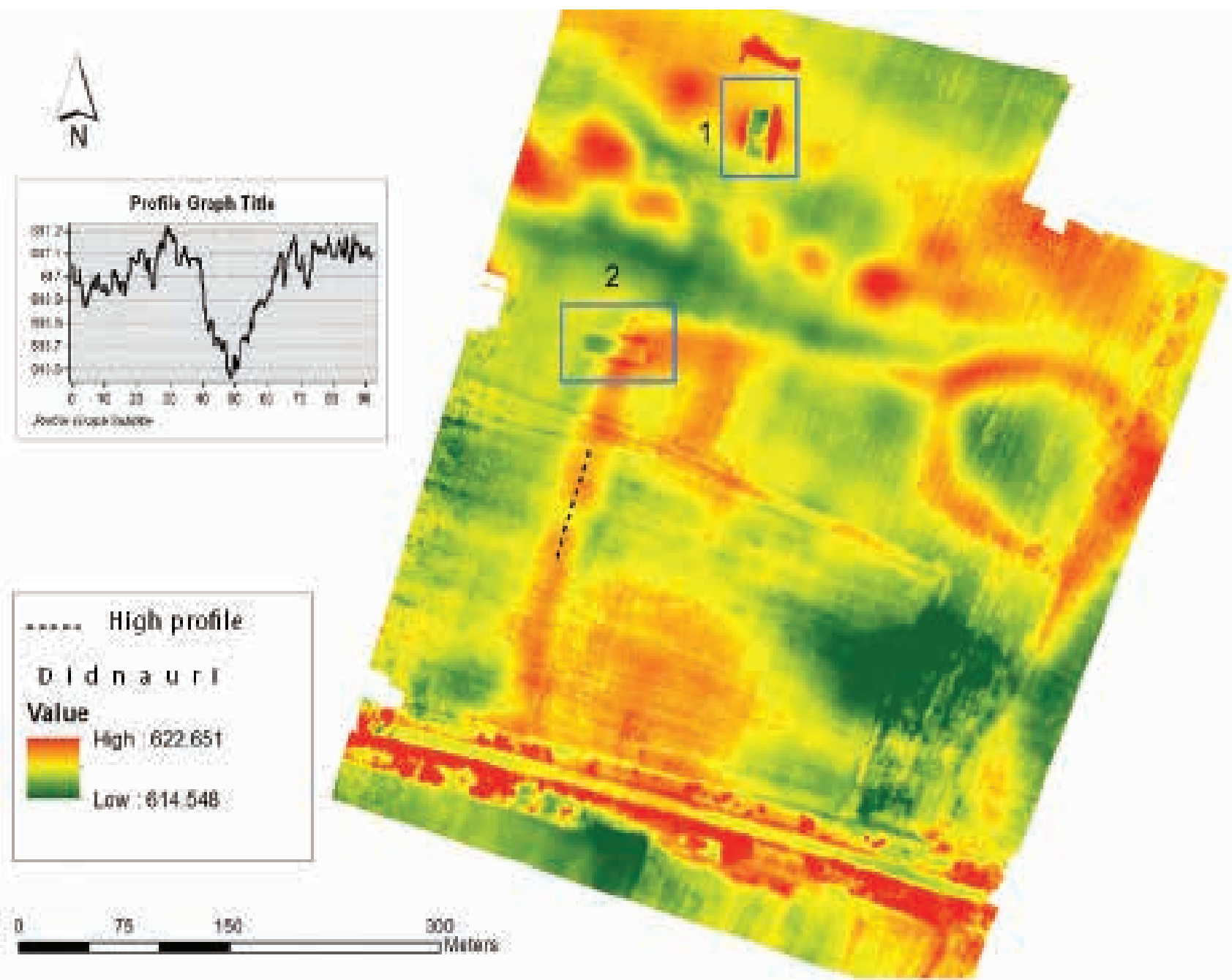

Digital elevation model of Didnaury ancient city. Dotted line shows the elevation profile at possible gates. DEM crated with close range Aerial photogrammetric survey 
NATIONAL AGENCY FOR CULTURAL HERITAGE PRESERVATION OF GEORGIA
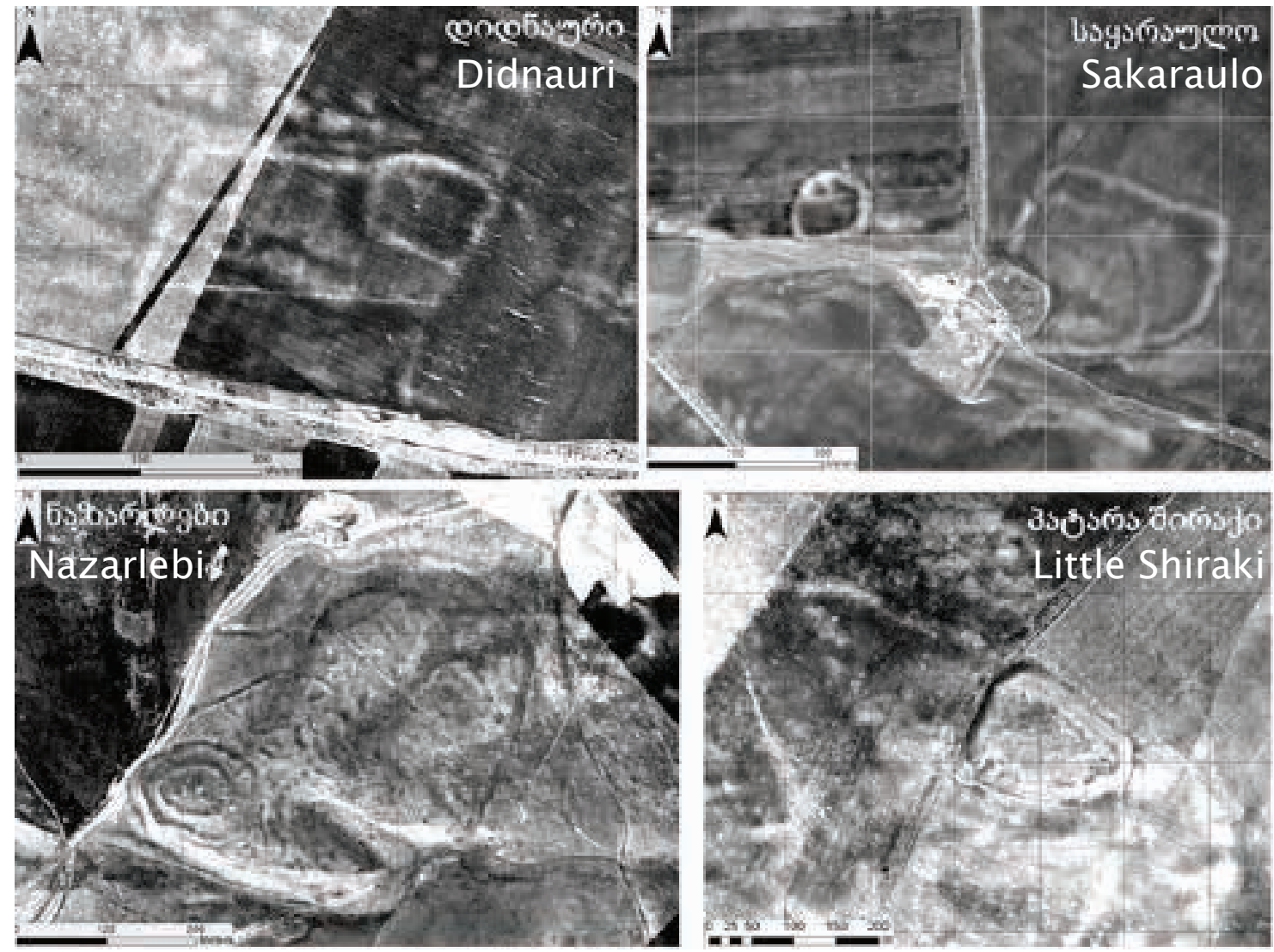

Bronze age settlements of Shiraqi plane as they seen on aerial Photos

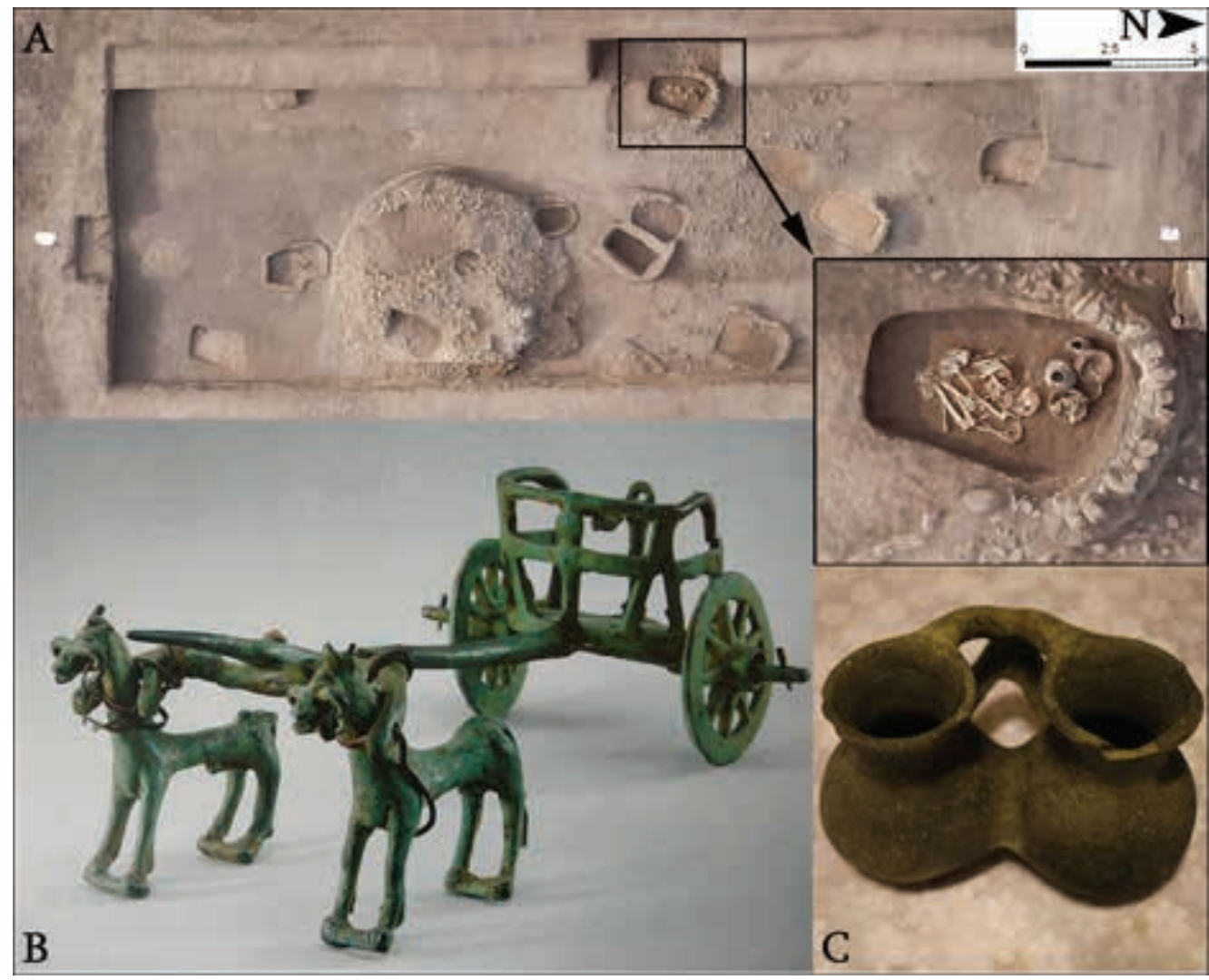

Excavation of Didnauri bronze age city 


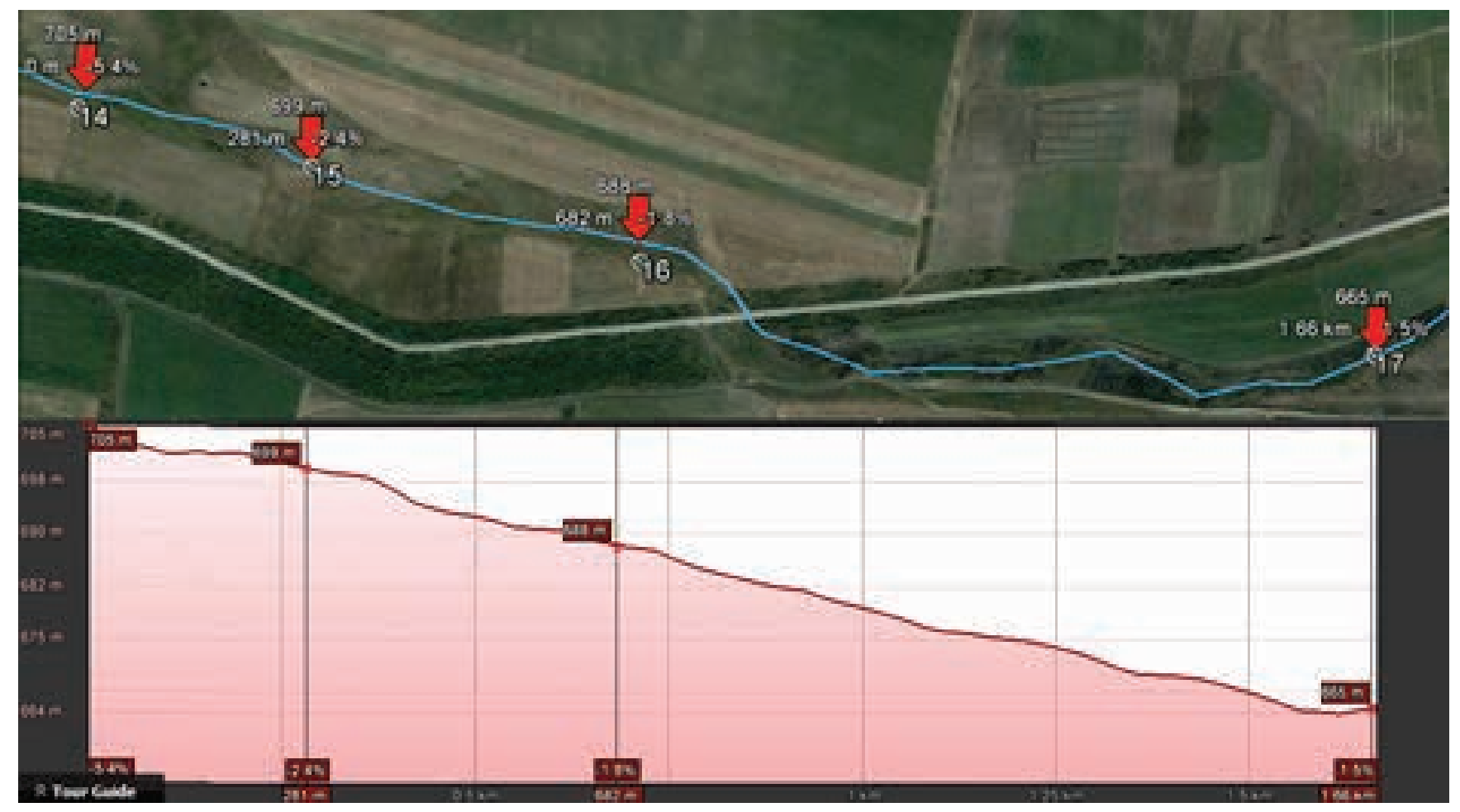

Elevation Profile of one of modeled palaeo hydro channels
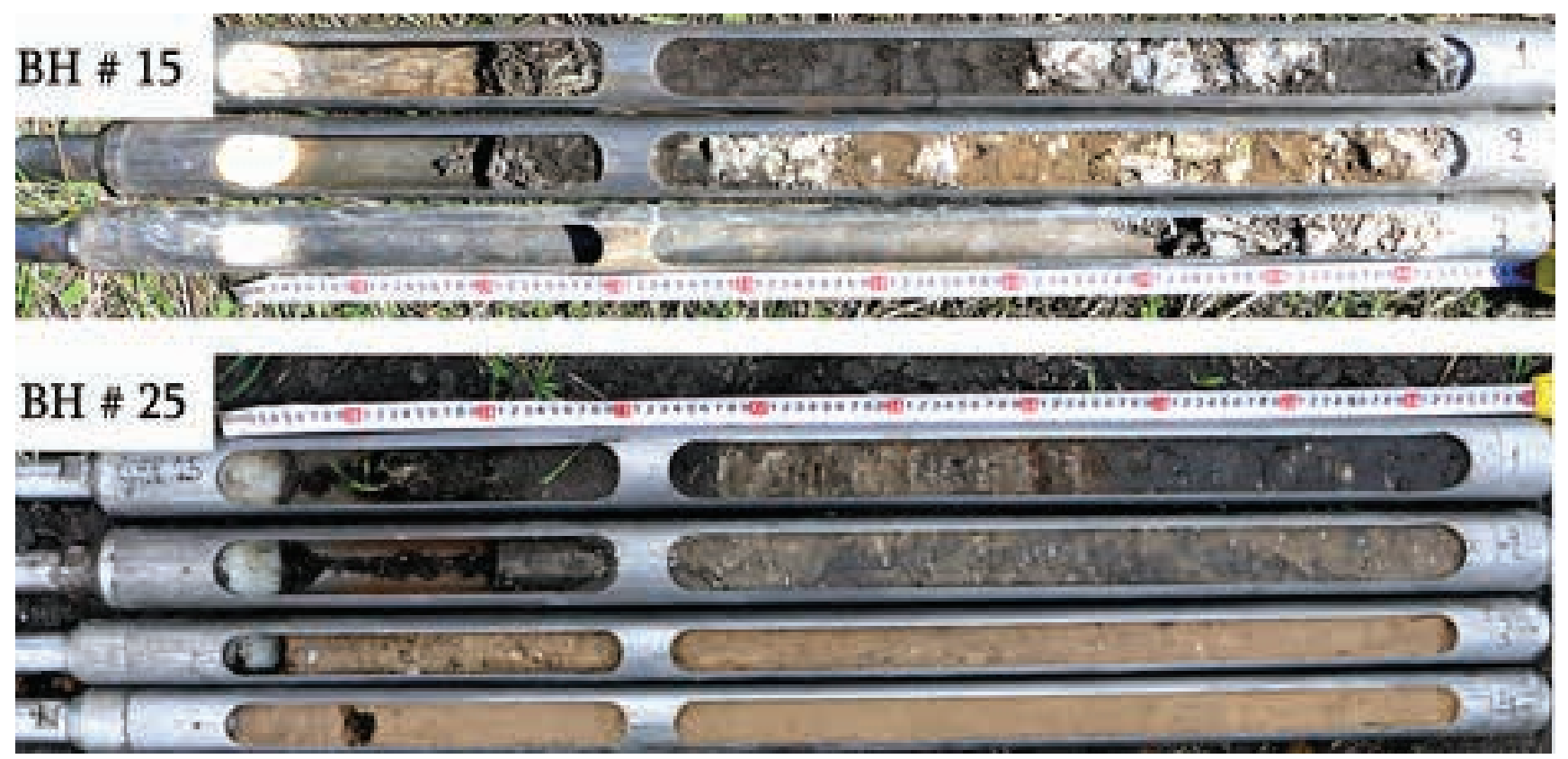

Sediment cores: \#15 from palaeo hydro channel, \#25 from possible palaeo Lake location 
NATIONAL AGENCY FOR CULTURAL HERITAGE PRESERVATION OF GEORGIA

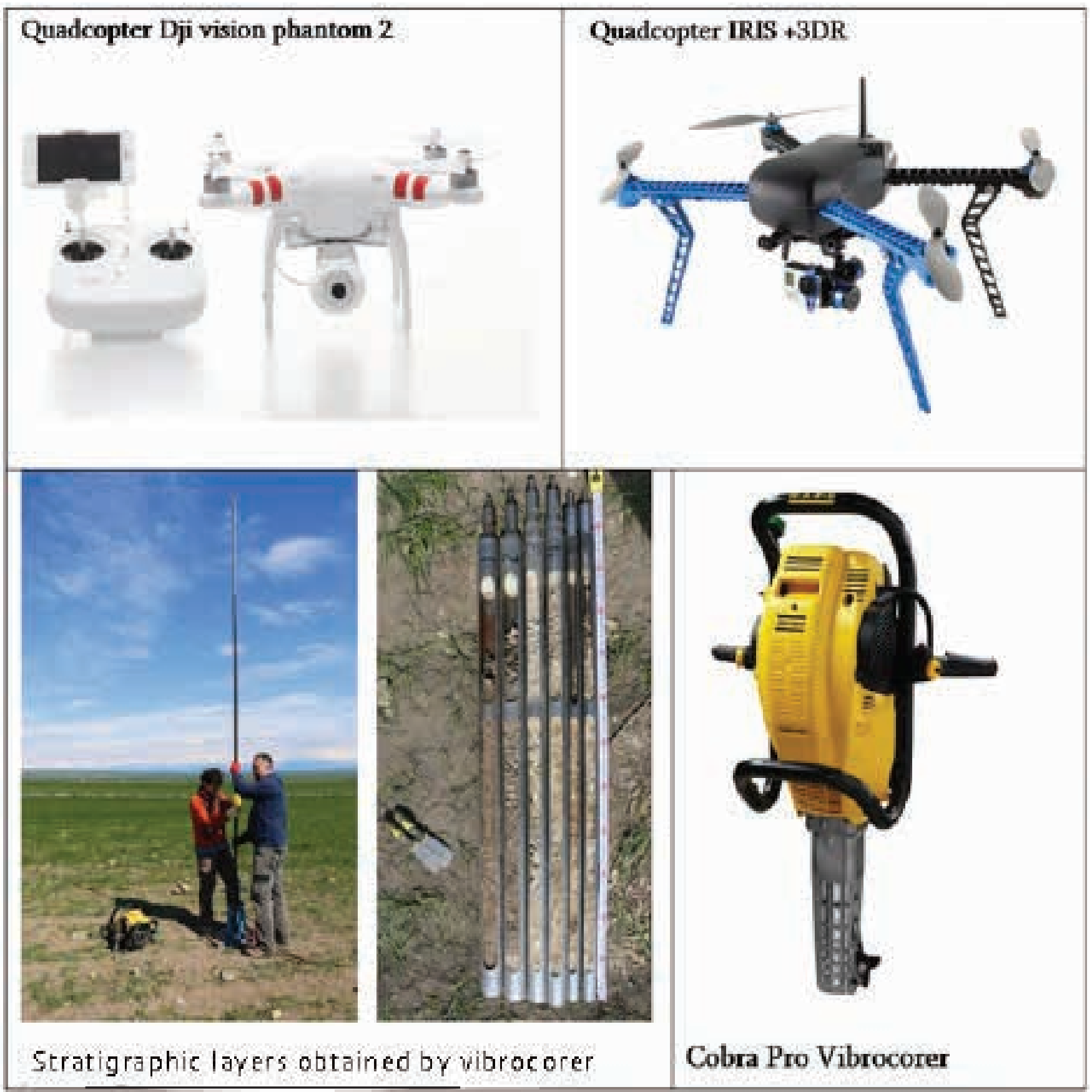

Equipment used during the multidisciplinary field work 


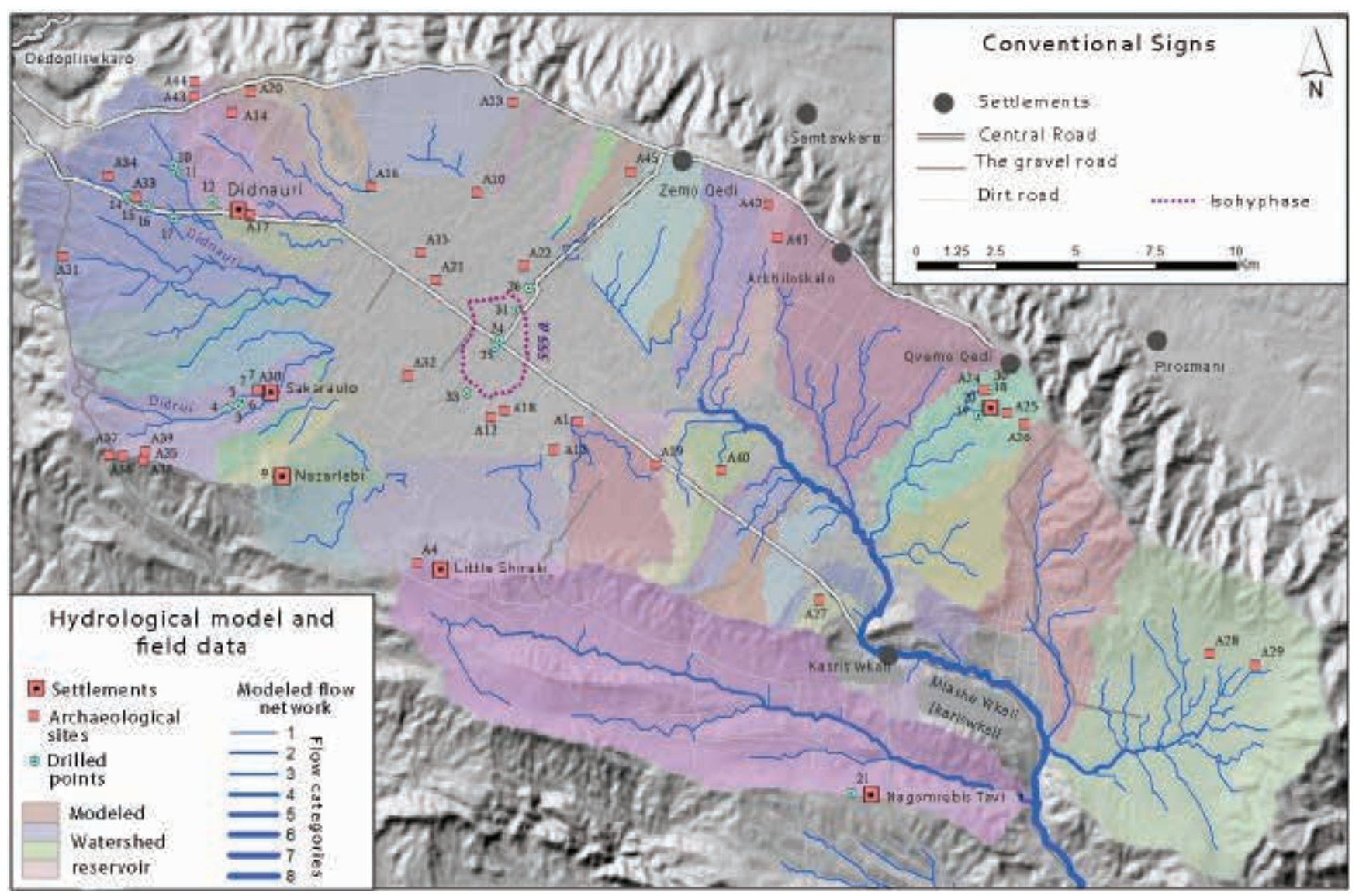

Modeled hydrographic Network and possible lake in the center of Shiraqi plane, in squares are shown major and minor archaeological sites. Circles show locations of drillings 